The European Journal of Public Health, Vol. 29, No. 4, 640-647

(C) The Author(s) 2019. Published by Oxford University Press on behalf of the European Public Health Association. All rights reserved. doi:10.1093/eurpub/ckz009 Advance Access published on 11 February 2019

\title{
Socioeconomic inequalities in disability in Europe: contribution of behavioral, work-related and living conditions
}

\author{
Bibiana Pérez-Hernández ${ }^{1,2}$, Jose R. Rubio-Valverde ${ }^{1}$, Wilma J. Nusselder ${ }^{1}$, Johan P. Mackenbach ${ }^{1}$ \\ 1 Department of Public Health, Erasmus Medical Center, Rotterdam, The Netherlands \\ 2 Department of Preventive Medicine and Public Health, School of Medicine, Universidad Autónoma de Madrid, Madrid, \\ Spain
}

Correspondence: Bibiana Pérez-Hernández, Department of Preventive Medicine and Public Health, Universidad Autónoma de Madrid, Calle del Arzobispo Morcillo 4, 28029 Madrid, Spain, Tel: +57 (1) 305 4749030, e-mail: arlynmb@yahoo.com

\begin{abstract}
Background: Previous studies have shown the existence of social inequalities in disability in many European countries. However, it is not clear what factors are associated with these inequalities. The aim of this study was to assess the contribution of behavioral factors, work-related factors and living conditions to educational inequalities in disability. Methods: We pooled data from the seventh wave of the European Social Survey (2014) which included self-reported disability measured with the Global Activity Limitations Indicator for 19 European countries. We used multivariate logistic regression to determine the contributions of behavioral factors, work-related and living conditions to educational inequalities in disability among respondents aged 3079. Results: We found that adjusting simultaneously for three groups of determinants (behavioral, work-related and living conditions) reduces the greatest proportion of inequalities in disability in both men and women, in a range $>70 \%$. Each group of determinants contributes substantially to explain inequalities in disability. Conclusions: Inequalities in disability are a major challenge for public health in most European countries. Our findings suggest that these inequalities can be reduced by diminishing inequalities in exposure to well-known health determinants.
\end{abstract}

\section{Introduction}

A cording to the World Health Organization disability prevalence is the result of a complex and dynamic relationship between health conditions and contextual factors, both personal and environmental. ${ }^{1}$ Several studies have shown a higher prevalence of disability among the poorly educated ${ }^{2}$ and persons with low economic resources. ${ }^{3}$ However, although disability is correlates with socioeconomic disadvantage, it is known that causality is multidirectional. ${ }^{1}$ Furthermore, trend studies have revealed the persistence of social inequalities in disability in Europe $e^{2,4}$ and other countries, like the USA ${ }^{5,6}$ and China.?

However, less is known about the influence of social determinants in disability. ${ }^{4,8}$ Studies aiming to explain social inequalities in health have often focused on other health outcomes, such as selfassessed health or mortality. ${ }^{9-12}$ In order to know how to reduce inequalities in disability more studies are needed with disability as an outcome.

We aim in this paper is to analyze how the context in which people live and work and their health behaviors can contribute to explain educational inequalities in disability. We hypothesize that lower educated people to have more unfavorable working and living conditions and less healthy living habits ${ }^{13,14}$ which could increase their likelihood of developing disability. ${ }^{15}$ In addition, the effect of these unfavorable living and working conditions is likely to partly go through less healthy behavior. ${ }^{16}$ We used the seventh round of European Social Survey (ESS), which has harmonized design, sampling and data collection methods. Furthermore, it provides a comparative Pan-European data set including many specific health determinants. ${ }^{17}$

\section{Methods}

\section{Data and study sample}

The 7th round of the ESS (2014) included a module on social inequalities in health with information on health-related behaviors, childhood, housing and work-related factors. The survey includes representative samples of non-institutionalized populations aged 15 years and older living in Austria, Belgium, Czech Republic, Denmark, Estonia, Finland, France, Germany, Hungary, Ireland, Lithuania, the Netherlands, Norway, Poland, Portugal, Slovenia, Spain, Sweden, Switzerland and the UK. ESS questionnaires were administered through face-to-face interviews at the respondent's place of residence. More information on the ESS survey can be found in Eikemo et al. ${ }^{17}$ and Fitzgerald and Jowell. ${ }^{18}$

We selected participants aged $30-79$ years old $(n=28887)$ and excluded data from Portugal because after stratification by sex and education, the sample was very small in size. We also excluded subjects without information on sex $(n=15)$, presence of disability $(n=57)$ and level of education $(n=160)$. Additionally, for analyses based on behavioral, work-related and living circumstances factors we excluded subjects with missing values in any of these variables, smoking $(n=38)$, alcohol $(n=5977)$, frequency of physical activity $(n=337)$, consumption of fruit and vegetables $(n=48)$ and body mass index $(n=868)$, job control $(n=1214)$, childhood financial difficulties $(n=472)$, household conflicts in childhood $(n=357)$, poor housing conditions $(n=170)$, financial strain $(n=132)$ and frequency of social meetings $(n=101)$. The percent of subjects with complete information in all study variables was $72 \%$ $(n=19882)$. 


\section{Study variables}

Disability occurs when a person's capacity to carry out basic actions of daily life and as well activities to societal participation are compromised or limited. ${ }^{1,2}$ We had measured disability with the Global Activity Limitation Indicator (GALI) ${ }^{19,20}$ using the question: 'Are you hampered in your daily activities in any way by any longstanding illness, disability, infirmity or mental health problem?' The participants had three possible answers: ${ }^{1}$ yes, a lot, ${ }^{2}$ yes, to some extent or $^{3}$ no. For the analysis, we dichotomized the variable in ${ }^{1}$ yes, a lot or yes to some extent vs. ${ }^{2}$ no. There is evidence of GALI is a global self-reported measure that reflects poor functional status and participation restriction among adults in population surveys. ${ }^{21}$ In addition, it has been shown that GALI is consistently correlates with more detailed measures for disability. ${ }^{2,19,20}$ Also, that it has a good and sufficient concurrent and predictive validity, and reliability. ${ }^{19-21}$

We used the respondent's education as a measure for socioeconomic position. The answer to the question: 'What is the highest level of education you have successfully completed?' was harmonized based on the International Standard Classification of Education (ISCED) $)^{22}$ and for the analyses we grouped it into three categories: low educated (ISCED I and II), medium educated (ISCED IIIa, IIIb and IV) and high educated (ISCED V and VI), this to capture the low educated groups in some European countries, where proportions of less educate groups were very small. ${ }^{23}$

Behavioral factors included smoking, frequency of alcohol consumption and frequency of physical activity, consumption of fruit and vegetables and body mass index. Smoking status was measured across four categories: current regular (includes 'I smoke daily' and 'I smoke but not every day'), occasional smoker (includes 'I have only smoked a few times' and 'I smoke but not every day'), exsmoker ('I don't smoke now but I used to') and never smoker ('I have never smoked'). For alcohol consumption, participants were asked the question: 'in the last 12 months, how often have you had a drink containing alcohol?'; we categorized the answers as: never, less than once a month, once a month, once a week, daily or almost daily. Frequency of physical activity was measured by the question 'on how many of the last 7 days you walked quickly, did sports and/or other physical activity for 30 minutes or longer?' and we categorized it as follows: daily, 4-6 times a week, 2-3 times a week, once a week, and never (0 times a week). Fruit and vegetable consumption was assessed separately by two questions: 'how often do you eat vegetables or salad, excluding potatoes?' and 'how often do you eat fruit, excluding drinking juice?' The answers for both were: three times or more a day, twice a day, once a day, less than once a day but at least four times a week, less than four times a week but at least once a week, less than once a week, never. For these analyses both questions were combined into consumption of vegetables and fruit at least once a day. The body mass index $\left(\mathrm{kg} / \mathrm{m}^{2}\right)$ was classified as underweight $\left(10-18.5 \mathrm{~kg} / \mathrm{m}^{2}\right)$, normal $\left(18.5-25 \mathrm{~kg} / \mathrm{m}^{2}\right)$, overweight $\left(25-30 \mathrm{~kg} / \mathrm{m}^{2}\right)$ and obese $\left(30-70 \mathrm{~kg} / \mathrm{m}^{2}\right)$.

Living conditions included housing conditions, financial difficulty and household conflict during childhood, current financial strain and lack of a social network. Housing conditions were assessed by asking the participants 'Do any of the problems listed on this card apply to your accommodation?': mold or rot in windows/doors or floors, damp walls or leaking roof, lack of an indoor flushing toilet, lack of a bathtub and shower, overcrowding, and extremely hot or extremely cold conditions'. The answers were 'yes', 'not' or 'Don't know', for analyses subjects were grouped as: those with no problems and those with $\geq 1$ problems in housing. Financial difficulty and household conflict during childhood were assessed by two questions: 'how often there was there serious conflict between the people living in your household when you were growing up?' and 'how often you and your family experienced severe financial difficulties when you were growing up?' Both had the same response options: always, often, sometimes, hardly ever and never. For the analysis it was dichotomized in almost never (never, hardly ever) and frequently (sometimes, often and always). Current financial strain was assessed by asking about current household income, and the response categories were: living comfortably on present income, coping on present income, difficult on present income, very difficult on present income. For the analysis, the answers were dichotomized into presence or absence of financial strain. The robustness of the respondent's social networks was assessed by the frequency of social contact and answers were grouped into two categories: more than once a week and less than once a week.

The work-related factors included physical, environmental, chemical hazards and psychosocial conditions. Environmental, chemical and ergonomic hazards were assessed by asking whether participants were ever exposed to a list of hazards. For the analysis answers were grouped into: exposure to no hazards, one hazard or two or more hazards. Finally, psychosocial working conditions were evaluated by job control which refers to the capacity to influence activities of the work organization and answers were grouped into low, moderate and high control.

Others variables included were: sex (male and female) and age.

\section{Statistical methods}

For the descriptive analyses, we calculated percentages for every group of determinants by country with unweighted data, except for the total. The prevalence of disability by educational level and country was standardized by direct method and using the European Standard Population and we calculated the simple prevalence difference between high and low educated groups. The frequency of disability was estimated, as well as their corresponding 95\% confidence intervals, in subgroups defined by social determinants adjusted by age and stratified by gender. We performed multivariate logistic regression to determine the contributions of social determinants to educational inequalities in disability, controlling for age, country and stratified by gender. Social determinants were grouped into three: behavioral, living conditions and work-related factors. Within every group of determinants each determinant was first evaluated separately and then each group in combination with all other determinants in the group (simultaneous). Next, we examined pairs of groups and all factors simultaneously. To assess the contribution of each group of determinants to educational inequalities in disability, we calculated the percentage of reduction in odds Ratio (OR), in the model with the determinant (model k) compared with the reference model which was adjusted for age and country (model 0 ). The percentage reduction in OR was calculated using the formula (OR model $0-\mathrm{OR}$ model $\mathrm{k}) /(\mathrm{OR}$ model $0-1$ ).

All analyses and estimations were obtained by using poststratification weights (Pspwght), which reduce sampling error and potential non-response bias. ${ }^{24}$ These weights are created by identifying the characteristics most related to non-response and applying an adjustment factor to the weights for the respondents to compensate for the non-respondents. The use of this adjustment reduces the bias in the estimates and can partially compensate for the loss data. 25,26

All analyses were age adjusted, stratified by sex and conducted using STATA v14.

\section{Results}

Our analysis includes 27895 participants from 19 European countries, with mean age of 51.7 years old, $52.0 \%$ of whom were female, $51.6 \%$ were in lowest educated group, $30.3 \%$ in the middle and $18.1 \%$ in the highest. Regarding behavioral factors $30.5 \%$ were smokers, $33.0 \%$ consumed alcohol less than once a month in the last 12 months, $55.9 \%$ consumed vegetables and fruit 
Table 1 Characteristics of the study population by education and gender (age 30-79)

\begin{tabular}{|c|c|c|c|c|c|c|}
\hline \multirow[b]{2}{*}{ Education } & \multicolumn{3}{|c|}{ Males $(n=13000)$} & \multicolumn{3}{|c|}{ Females $(n=14722)$} \\
\hline & $\begin{array}{l}\text { Low educated } \\
(n=5858)\end{array}$ & $\begin{array}{l}\text { Medium educated } \\
(n=4072)\end{array}$ & $\begin{array}{l}\text { Highly educated } \\
(n=3070)\end{array}$ & $\begin{array}{l}\text { Low educated } \\
(n=6144)\end{array}$ & $\begin{array}{l}\text { Medium educated } \\
(n=4823)\end{array}$ & $\begin{array}{l}\text { Highly educated } \\
(n=3755)\end{array}$ \\
\hline Age, years & $55.8(0.2)$ & $52.0(0.2)$ & $50.6(0.2)$ & $57.2(0.2)$ & $52.3(0.2)$ & $48.2(0.2)$ \\
\hline \multicolumn{7}{|l|}{ Behavioral factors } \\
\hline Current regular (daily smoker) & 31.5 & 25.6 & 13.7 & 23.1 & 17.8 & 9.3 \\
\hline Ex-smoker & 31.6 & 29.4 & 29.2 & 20.3 & 19.1 & 23.6 \\
\hline Never smoker & 34.1 & 41.0 & 53.1 & 54 & 59.7 & 63.3 \\
\hline Occasional smoker & 2.7 & 3.9 & 3.9 & 2.6 & 3.4 & 3.7 \\
\hline \multicolumn{7}{|l|}{ Alcohol consumption (\%) } \\
\hline Never & 26.4 & 21.9 & 24.0 & 45.5 & 36.1 & 36.0 \\
\hline Less than once a month & 30.8 & 33.1 & 35.5 & 30.1 & 35.9 & 35.4 \\
\hline Once a month & 18.1 & 21.9 & 21.8 & 11.8 & 15.1 & 17.5 \\
\hline Once a week & 19.1 & 20.2 & 16.4 & 11.0 & 12.2 & 10.2 \\
\hline Daily or almost daily & 5.6 & 2.9 & 2.3 & 1.6 & 0.7 & 0.9 \\
\hline \multicolumn{7}{|l|}{$\begin{array}{l}\text { Consumes vegetables \& fruit at } \\
\text { least once a day }(\%)\end{array}$} \\
\hline Yes & 44.3 & 50.9 & 59.3 & 59.3 & 63.9 & 73.4 \\
\hline \multicolumn{7}{|l|}{ Frequency of physical activity (\%) } \\
\hline Daily & 24.0 & 22.8 & 20.1 & 21.9 & 22.8 & 20.8 \\
\hline 4-6 times a week & 16.6 & 21.2 & 24.4 & 16.1 & 20.3 & 23.9 \\
\hline 2-3 times a week & 20.7 & 26.8 & 31.2 & 21.0 & 25.3 & 29.8 \\
\hline Once a week & 8.9 & 10.1 & 10.8 & 9.4 & 9.7 & 10.0 \\
\hline Never & 29.7 & 19.1 & 13.5 & 31.6 & 21.9 & 15.4 \\
\hline \multicolumn{7}{|l|}{ Body mass index $\left[\mathrm{kg} / \mathrm{m}^{2}\right](\%)$} \\
\hline Underweight (10-18.5) & 0.4 & 0.6 & 0.6 & 2.1 & 2.0 & 2.9 \\
\hline Normal (18.5-25) & 30.0 & 33.6 & 41.5 & 41.8 & 47.4 & 59.7 \\
\hline Overweight (25-30) & 48.4 & 48.7 & 45.5 & 34.4 & 34.1 & 26.8 \\
\hline Obese $(30-70)$ & 21.1 & 17.0 & 12.4 & 21.7 & 16.5 & 10.6 \\
\hline \multicolumn{7}{|l|}{ Work-related conditions } \\
\hline \multicolumn{7}{|l|}{ Material hazards } \\
\hline No hazards & 31.2 & 42.0 & 61.3 & 62.6 & 67.1 & 69.3 \\
\hline One hazard & 21.4 & 19.2 & 17.7 & 20.5 & 19.2 & 19.2 \\
\hline Two or more & 47.3 & 38.8 & 21.0 & 16.8 & 13.6 & 11.4 \\
\hline \multicolumn{7}{|l|}{ Ergonomic hazards } \\
\hline No hazards & 27.2 & 37.1 & 61.4 & 48.9 & 53.5 & 62.3 \\
\hline One hazard & 27.8 & 26.5 & 20.9 & 30.4 & 28.9 & 25.2 \\
\hline Two or more & 45.0 & 36.4 & 17.7 & 20.8 & 17.6 & 12.6 \\
\hline \multicolumn{7}{|l|}{ Job control } \\
\hline Low control & 49.5 & 39.3 & 24.1 & 58.0 & 50.8 & 32.3 \\
\hline Moderate control & 21.0 & 26.2 & 32.8 & 18.0 & 24.3 & 35.9 \\
\hline High control & 29.5 & 34.5 & 43.0 & 24.0 & 24.8 & 31.7 \\
\hline \multicolumn{7}{|l|}{ Living circumstances } \\
\hline \multicolumn{7}{|l|}{ Problems with housing (\%) } \\
\hline Yes & 13.6 & 12.4 & 9.5 & 15.1 & 13.0 & 12.8 \\
\hline \multicolumn{7}{|l|}{$\begin{array}{l}\text { Frequency of financial difficulties } \\
\text { during childhood }(\%)\end{array}$} \\
\hline Almost never & 49.3 & 55.5 & 70.6 & 49.1 & 50.6 & 64.7 \\
\hline Frequently & 50.7 & 44.5 & 29.3 & 50.9 & 49.4 & 35.2 \\
\hline \multicolumn{7}{|l|}{ Financial strain (\%) } \\
\hline Yes & 25.8 & 17.4 & 6.9 & 29.8 & 25.1 & 10.7 \\
\hline \multicolumn{7}{|l|}{$\begin{array}{l}\text { Frequency of conflicts } \\
\text { household during childhood (\%) }\end{array}$} \\
\hline Almost never & 63.5 & 62.1 & 68.3 & 60.9 & 58.8 & 59.4 \\
\hline Frequently & 36.5 & 37.8 & 31.6 & 39.1 & 41.2 & 40.6 \\
\hline $\begin{array}{l}\text { Frequency of social meetings } \\
\text { (social network) (\%) }\end{array}$ & & & & & & \\
\hline Almost never & 24.2 & 23.1 & 16.8 & 25.7 & 26.0 & 17.8 \\
\hline Sometimes & 42.9 & 43.4 & 44.0 & 40.2 & 42.0 & 42.7 \\
\hline Frequently & 32.8 & 32.6 & 39.2 & 34.1 & 31.9 & 39.4 \\
\hline
\end{tabular}

Source: European Social Survey Round 7, 2014 Statistics present are unweighted. For age, the mean (SD) is provide.

at least once a day (except juice and potatoes), $24.3 \%$ did sports or other physical activity, 2 or 3 days in the last week and $39.7 \%$ were overweight. Additionally, $46.9 \%$ had frequent financial conflicts while growing up and more than $27.0 \%$ were ever exposed to more than two material or ergonomic hazards (table 1).

The prevalence of disability was higher in females, increased with age and was higher in low educated groups. In males it was $25.1 \%$ (95\% CI: $24.3-25.8 \%)$ and 29.0\% (28.2-29.7\%) in females. Among the low educated, the prevalence of disability was $32.0 \%$ (95\% CI $30.9-33.1 \%)$ in males and $36.0 \%(95 \%$ CI $34.9-37.1 \%)$ in females, and among the high educated it was $15.4 \%$ (95\% CI $14.0-16.9 \%)$ in males and $18.9 \%$ (95\% CI $17.3-20.4 \%)$ in females (figure 1) (Supplementary appendix S1).

In an analysis stratified by country, the age-standardized prevalence of disability varied between $16.4 \%$ in Ireland and $39.0 \%$ in Slovenia, and in almost all countries disability was 


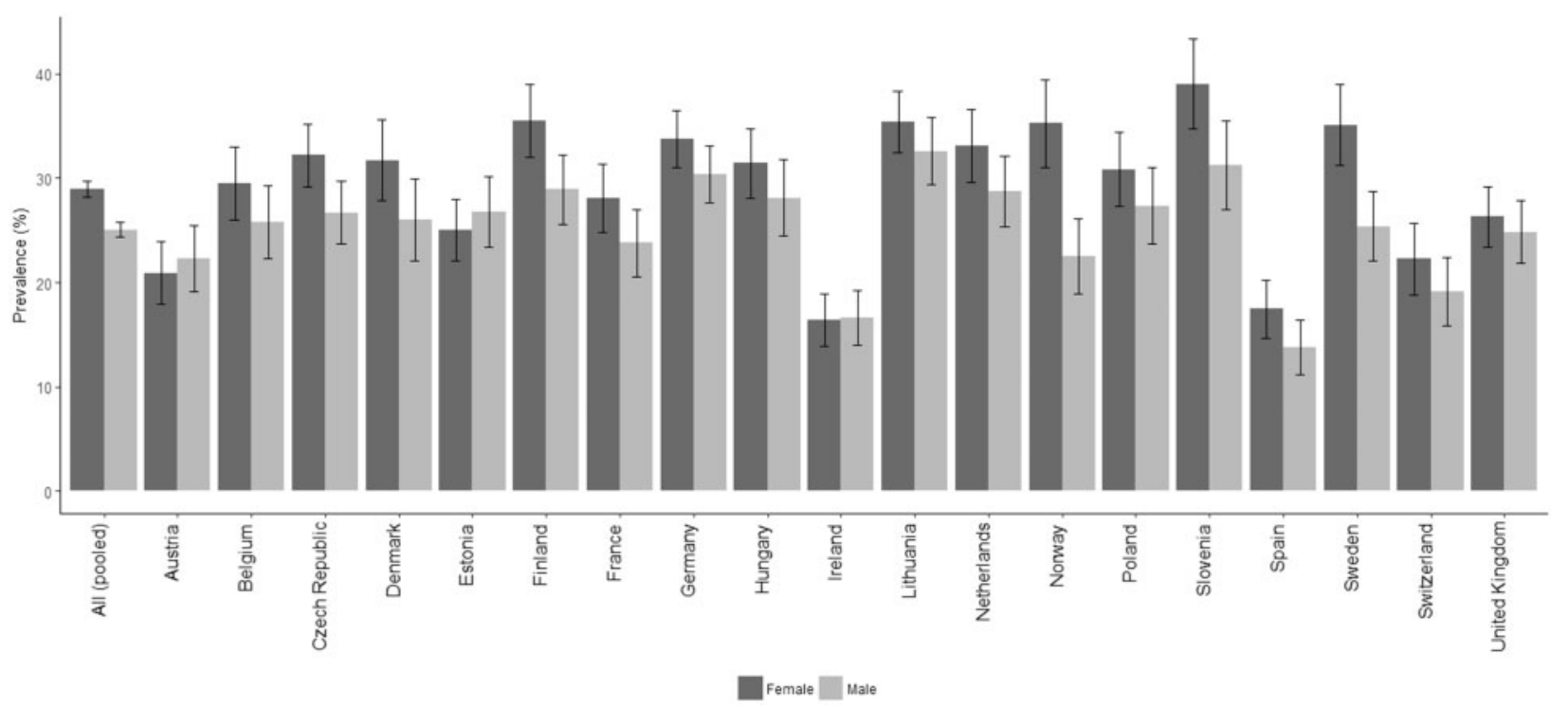

Figure 1 Prevalence of disability by country and gender (age 30-79)

higher for women and the low educated group. Slovenia and Lithuania showed the highest prevalence of disability for both genders, while Ireland and Spain had the lowest. Countries with the largest educational inequalities in disability were Lithuania, Estonia and Slovenia. In addition, Estonia was the country with the largest difference between men and women in educational inequalities in disability. On the other hand, countries with the smallest inequalities in disability were Ireland, the UK and the Nordic countries. The Czech Republic does not have a significantly different prevalence of disability between the high and low educated (figure 1) (Supplementary appendix S1).

In an analysis adjusted for age, the frequency of disability was higher among females, daily smokers, persons who consume alcohol frequently and those who do not consume fruits and vegetables at least once a day, in obese females and underweight males, and in persons physically inactive (who do not do physical activity at least once per week), In addition, the frequency of disability was higher in participants exposed to two or more material and ergonomic hazards and in those with low capacity to influence activities of the work organization. Moreover, disability was higher in persons who reported frequent financial difficulties and household conflict while growing up, in persons who live in poor conditions, in persons with financial strain and in persons who almost never have social contacts (table 2).

Table 3 presents the contribution of different groups of factors to the educational inequalities in disability relative to the reference model. The reference model was adjusted by age and county (model 0) and showed higher odds of being disabled for the low educated group in comparison with the high educated group for both males (OR 2.02; 95\% CI 1.78-2.30) and females (OR 2.01; 95\% CI 1.78-2.27).

These ORs for disability were attenuated when behavioral factors, work-related factors or living conditions were added simultaneously to the model. Separate analyses showed that frequency of physical activity was the behavior that most reduced the ORs among males, while among females was the frequency of alcohol consumption. Similarly, for work-related factors, the exposure to ergonomic hazards was what attenuated more the ORs for both males and females. And finally, for living conditions, financial strain was the factor that most reduced the ORs the most, both females and males.

In the analysis including several factors simultaneously, we found that behavioral factors among females and work-related conditions among males were the determinants that contributed most to explaining educational inequalities in disability. The highest reduction in ORs was obtained when we adjusted simultaneously for the three groups of factors. This reduced the ORs by more than $70.0 \%$ among both males and females.

\section{Discussion}

The age-standardized prevalence of disability was higher among women and the low educated in almost all countries, but the magnitude of these inequalities differed substantially between countries. In the pooled dataset, work-related conditions were the most important contributor among men, and behavioral factors among women, but there were large variations between countries in the contribution of determinants.

The main strengths of this study include that disability was measured with a validated disability indicator which was harmonized across European countries, ${ }^{19,20}$ and that we conducted individual-level and simultaneous analyses for different groups of determinants to determine how these contributed to the formation and persistence of educational disparities in disability among males and females in Europe.

However, our study also has important limitations. Firstly, the fact that all measures were self-reported, may be underreporting of consumption in some behavioral factors, due to the influence of cultural differences or social desirability of answers. ${ }^{1,17}$ Reporting differences may explain the lower prevalence of disability in countries like Spain, where there is a strong intra-household support and care for persons with disabilities. ${ }^{27}$ Secondly, the large variation of response rates between countries, may have affected estimates of disability rates ${ }^{28}$ especially in countries with a low response rates (e.g. Germany) (Supplementary appendix S2). Therefore, cross-national comparison for disability rates should be treated with caution. Thirdly, the crosssectional study design, does not allow causal inferences. However, our aim was to analyze which of factors analyzed were more associated with inequalities in disability prevalence, independent of the causal direction. ${ }^{29}$ Additionally, our results may be affected by selective non-response bias (e.g. respondents with alcohol consumption may be less likely to participate) and as well by recall bias, especially in estimates related to financial difficulties in childhood. Finally, the fact that some determinants were measured with a single dichotomized response question, may have underestimated their contribution to explain inequalities in disability.

Similar to previous studies in Europe, our results showed that living in adverse conditions ${ }^{30}$ and being exposed to work-related risks $^{8}$ have an effect on behaviors; ${ }^{23}$ which implies that they 
Table 2 Frequency of disability according social determinants, by gender

Disability

\begin{tabular}{|c|c|c|c|c|c|c|}
\hline & \multicolumn{6}{|c|}{ Disability } \\
\hline \multicolumn{7}{|l|}{ Behavioral factors } \\
\hline \multicolumn{7}{|l|}{ Smoking status (\%) } \\
\hline Current regular (daily smoker) & 1876 & $33.8(32.4-35.2)$ & 980 & $30.3(28.6-32.1)$ & 896 & $37.1(34.9-39.2)$ \\
\hline Occasional smoker & 208 & $26.1(22.9-29.4)$ & 95 & $22.5(18.2-26.9)$ & 113 & $29.4(24.6-34.3)$ \\
\hline \multicolumn{7}{|l|}{ Alcohol consumption } \\
\hline Never & 2083 & $26.1(24.9-27.3)$ & 807 & $25.6(23.7-27.5)$ & 1276 & $27.1(25.6-28.6)$ \\
\hline Less than once a month & 1876 & $25.9(24.8-27.1)$ & 834 & $22.6(21.1-24.2)$ & 1042 & $29.3(27.6-31.0)$ \\
\hline Once a month & 878 & $24.5(22.9-26.1)$ & 520 & $23.2(21.2-25.1)$ & 358 & $25.9(23.3-28.5)$ \\
\hline Once a week & 870 & $26.7(24.9-28.4)$ & 551 & $26.1(23.9-28.3)$ & 319 & $26.5(23.7-29.3)$ \\
\hline Daily or almost daily & 182 & $30.0(25.7-34.3)$ & 146 & $29.2(24.6-33.9)$ & 36 & $28.2(19.0-37.4)$ \\
\hline Never & 2750 & $39.1(37.8-40.5)$ & 1192 & $37.1(35.1-39.1)$ & 1558 & $41.0(39.1-42.8)$ \\
\hline \multicolumn{7}{|l|}{$\begin{array}{l}\text { Consumes vegetables \& fruit at } \\
\text { least once a day }\end{array}$} \\
\hline Yes & 4385 & $25.8(25.0-26.6)$ & 1660 & $23.5(22.4-24.7)$ & 2725 & $27.9(26.9-28.9)$ \\
\hline No & 3636 & $32.0(31.0-33.0)$ & 1866 & $29.2(28.0-30.5)$ & 1770 & $34.6(33.1-36.1)$ \\
\hline \multicolumn{7}{|l|}{ Body mass index $\left[\mathrm{kg} / \mathrm{m}^{2}\right]$} \\
\hline Underweight (10-18.5) & 139 & $35.0(29.7-40.2)$ & 29 & $43.7(30.2-57.2)$ & 110 & $34.8(29.0-40.6)$ \\
\hline Normal (18.5-25) & 2581 & $24.8(23.8-25.7)$ & 1041 & $25.3(23.8-26.7)$ & 1540 & $24.9(23.7-26.2)$ \\
\hline Overweight (25-30) & 3015 & $26.5(25.6-27.5)$ & 1523 & $23.5(22.3-24.7)$ & 1492 & $29.7(28.2-31.2)$ \\
\hline Obese (30-70) & 2025 & $39.5(37.9-41.0)$ & 852 & $34.6(32.5-36.8)$ & 1173 & $44.1(41.8-46.4)$ \\
\hline \multirow{2}{*}{\multicolumn{7}{|c|}{$\begin{array}{l}\text { Work-related conditions } \\
\text { Material hazards }\end{array}$}} \\
\hline & & & & & & \\
\hline No hazards & 3789 & $23.6(22.8-24.4)$ & 1184 & $21.0(19.7-22.2)$ & 2605 & $26.2(25.2-27.3)$ \\
\hline One hazard & 1741 & $30.6(29.2-32.0)$ & 715 & $26.8(24.8-28.7)$ & 1026 & $34.0(32.1-36.0)$ \\
\hline \multicolumn{7}{|l|}{ Living circumstances } \\
\hline \multicolumn{7}{|l|}{$\begin{array}{l}\text { Frequency of financial conflicts } \\
\text { while growing up }\end{array}$} \\
\hline Almost never & 3465 & $23.7(22.9-24.5)$ & 1576 & $22.0(21.0-23.1)$ & 1889 & $25.2(24.1-26.4)$ \\
\hline Frequently & 4418 & $33.7(32.8-34.7)$ & 1891 & $31.5(30.1-32.8)$ & 2527 & $35.8(34.4-37.1)$ \\
\hline \multirow{2}{*}{\multicolumn{7}{|c|}{$\begin{array}{l}\text { Frequency of conflicts } \\
\text { household during childhood }\end{array}$}} \\
\hline & & & & & & \\
\hline Frequently & 3629 & $35.0(34.0-36.1)$ & 1524 & $32.7(31.1-34.2)$ & 2105 & $37.1(35.7-38.6)$ \\
\hline Problems with housing & & & & & & \\
\hline Yes & 1378 & $39.2(37.4-41.1)$ & 554 & $36.4(33.6-39.1)$ & 824 & $41.7(39.2-44.2)$ \\
\hline No & 6599 & $26.7(26.1-27.3)$ & 2960 & $24.9(24.1-25.8)$ & 3639 & $28.3(27.4-29.2)$ \\
\hline Financial strain & & & & & & \\
\hline Yes & 2581 & $42.8(41.4-44.3)$ & 1024 & $41.5(39.3-43.6)$ & 1557 & $44.2(42.3-46.2)$ \\
\hline No & 5433 & $24.4(23.8-25.1)$ & 2499 & $22.7(21.8-23.6)$ & 2934 & $26.0(25.1-26.9)$ \\
\hline Frequency of social meetings & & & & & & \\
\hline Almost never & 2284 & $33.3(32.0-34.6)$ & 991 & $31.5(29.7-33.4)$ & 1293 & $35.0(33.2-36.8)$ \\
\hline Sometimes & 3090 & $26.0(25.1-26.9)$ & 1414 & $24.1(22.9-25.4)$ & 1676 & $27.7(26.4-29.0)$ \\
\hline Frequently & 2626 & $28.2(27.1-29.2)$ & 1113 & $25.9(24.4-27.3)$ & 1513 & $30.3(28.8-31.8)$ \\
\hline
\end{tabular}

Source: European Social Survey Round 7, 2014.

Percents are weighted for 19 countries. Adjusted by sex and age. $(95 \% \mathrm{Cl})$ Confidence Interval $95 \%$.

overlap $^{31}$ and it is through their interrelationship how they contribute to explain inequalities in many diseases and health problems, such as disability. ${ }^{8,32-36}$ What we add to the previous literature is quantitative estimates of the contribution of these risk factors to social inequalities in disability.
The cross-national variation in the prevalence of disability was wide, in line with what was described in previous studies in Europe. ${ }^{2,3}$ Our results also showed high prevalences of disability in both countries with middle and those with high average income. However, the patterns of variation in disability prevalence between 
Table 3 Educational inequalities in disability by gender (age 30-79), before and after adjust by social determinants and OR change percent

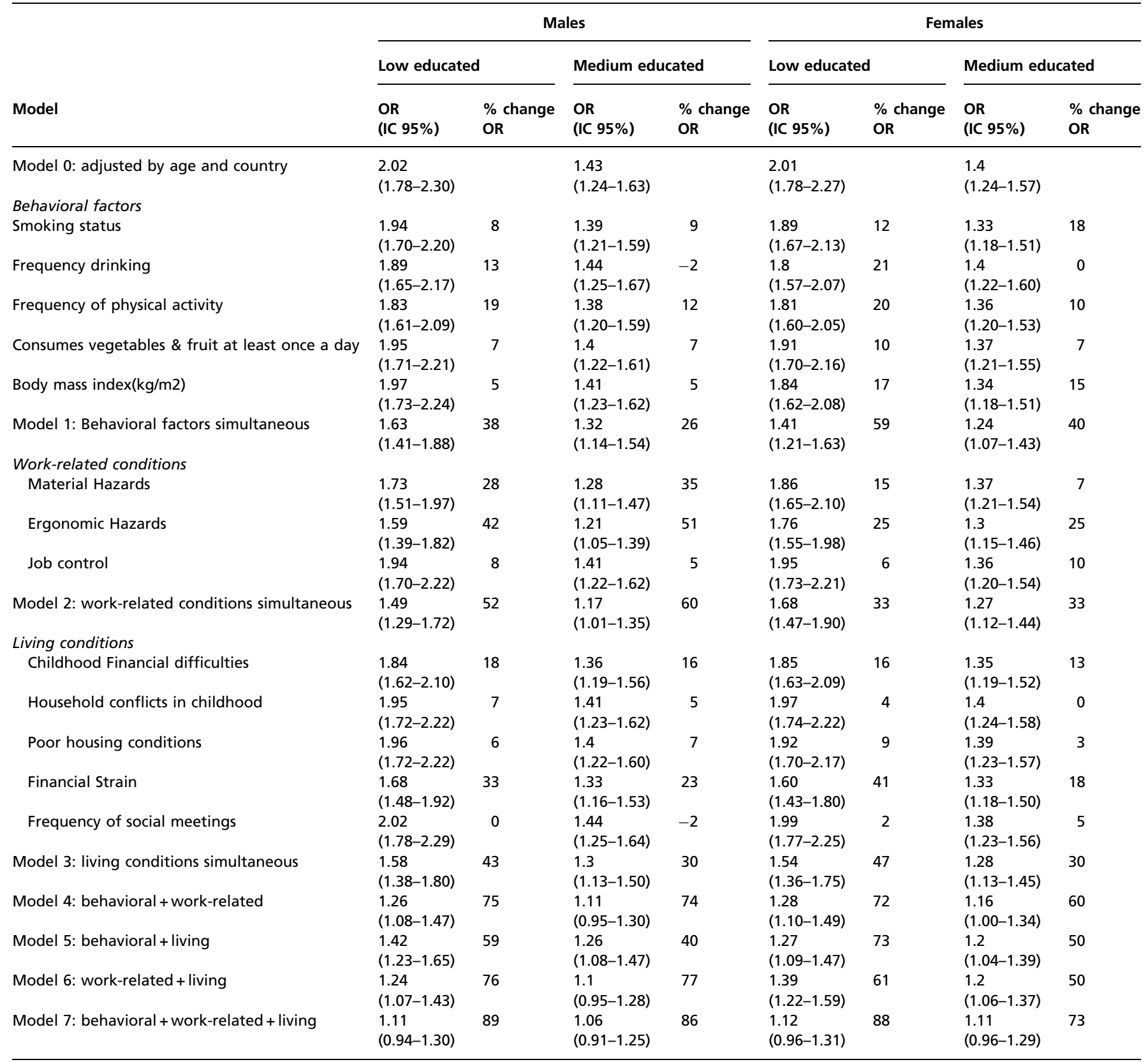

Source: European Social Survey Round 7, 2014.

All models are adjusted by age and country and high educated was the reference category.

Model 0: adjusted by age and country.

Model 1: Model $0+$ smoking status + frequency drinking + frequency of physical activity + consumes vegetables $\&$ fruit + body mass index $\left(\mathrm{kg} / \mathrm{m}^{2}\right)$.

Model 2: Model $0+$ material hazards + ergonomic hazards + job control.

Model 3: Model $0+$ Childhood financial difficulties + household conflicts in childhood + poor housing conditions + financial strain + frequency of social meetings.

Model 4: Model $1+$ Model 2.

Model 5: Model $1+$ Model 3.

Model 6: Model 2+Model 3.

Model 7: Model $1+$ Model $2+$ Model 3.

$\%$ change in Odds Ratio were calculated by: $\left[\left(\mathrm{OR}_{(\text {Model adjusted age and country) }}-\mathrm{OR}_{(\text {Model adjusted by social determinants) })} /\right.\right.$

$\left.\left(\mathrm{OR}_{(\text {Model adjusted age and country) }}-1\right)\right] \times 100$.

countries was not always the same as those reported in previous studies. ${ }^{2,3}$ The differences can perhaps be explained by the fact that other studies used non-harmonized data, which increases the risk of bias due to variation in data collection and survey characteristics.

Our results suggest that among males, work-related factors explain most of the inequalities in disability while among females behavioral factors explained relatively more. In addition, in both males and females more than $60 \%$ of educational differences in disability were explained by behavioral and work-related factors taken together. Our findings are consistent with those reported by Sainio et al. ${ }^{8}$ who showed that in both females and males more than half of the differences in self-reported mobility limitations were 
explained by behavioral and work-related factors simultaneously. In the same sense, Stansfeld et al. ${ }^{35}$ reported that behavioral factors are more important than living conditions (material deprivation and psychosocial factors) in explaining inequalities in physical function and disability.

One explanation for our findings is that education as a personal and social resource provides cognitive abilities and personality profiles which determine health-related behavior and influence the accessibility to better environmental conditions, thereby reducing the risk of diseases and disability. ${ }^{37,38}$ The fact that among females behavioral factors explain more, and among males work-related factors explain more of the inequalities in disability is not surprising in view of the fact that more men are involved in paid work, and that health-related beliefs and behaviors are strongly structured by gender roles, as described in previous studies. ${ }^{39}$

Inequalities in disability are a major challenge for public health in most European countries. Our findings suggest that each group of determinants (behavioral, work-related and living conditions) contribute substantially to explain inequalities in disability. Preventive actions focusing on health-related behaviors, working and living conditions in the lower socioeconomic groups can be reduce inequalities in disability. Further research is needed to better understand these pathways, and to evaluate interventions to reduce inequalities in disability.

\section{Supplementary data}

Supplementary data are available at EURPUB online.

\section{Funding}

This study was conducted as part of the LIFEPATH project, which has been financially supported by the European Commission (Horizon 2020 grant number 633666).

\section{Disclaimer}

The funders had no role in study design, data collection and analysis, decision to publish or preparation of the manuscript. The following data from the European Social Survey were used: ESS Round 4: European Social Survey Round 4 Data (2008). Data file edition 4.4. ESS Round 5: European Social Survey Round 5 Data (2010). Data file edition 3.3. ESS Round 6: European Social Survey Round 6 Data (2012). Data file edition 2.3. NSD - Norwegian Centre for Research Data, Norway - Data Archive and distributor of ESS data for ESS ERIC.

Conflicts of interest: We have not conflicts of interest to declare.

\section{Key points}

- Our results suggest that the factors that contributed the most to explain educational inequalities in disability were work-related among males and behavioral among females. There are large variations between countries in the contribution of determinants.

- This study offers a comparison of educational inequalities in the prevalence of disability in 19 European countries, using the Global Activity Limitation Indicator (GALI).

- This work examines the relative contribution of behavioral, work-related and living conditions factors in the explanation of educational inequalities in the prevalence of disability.

- These findings suggest that inequalities in disability can be tackled by preventive actions focusing on health-related behaviors and working conditions in the lower socioeconomic groups.

\section{References}

1 World Health Organization \& World Bank. World Report on Disability 2011, Geneva: World Health Organization, 2011. Available at: http://www.who.int/iris/ handle/10665/44575 (6 July 2018, date last accessed).

2 Cambois E, Solé-Auró A, Brønnum-Hansen H, et al. Educational differentials in disability vary across and within welfare regimes: a comparison of 26 European countries in 2009. J Epidemiol Community Health 2016;70:331-8.

3 Hosseinpoor AR, Stewart Williams JA, Gautam J, et al. Socioeconomic inequality in disability among adults: a multicountry study using the World Health Survey. Am J Public Health 2013;103:1278-86.

4 Klijs B, Nusselder WJ, Looman CW, Mackenbach JP. Educational disparities in the burden of disability: contributions of disease prevalence and disabling impact. Am J Public Health 2014;104:e141-8.

5 Molla MT, Madans JH, Wagener DK. Differentials in adult mortality and activity limitation by years of education in the United States at the end of the 1990s. Popul Dev Rev 2004;30:625-46.

6 Schoeni RF, Martin LG, Andreski PM, Freedman VA. Persistent and growing socioeconomic disparities in disability among the elderly: 1982-2002. Am J Public Health 2005;95:2065-70.

7 Wang Z, Chen G, Guo C, et al. Socioeconomic Inequalities and Multi-Disability among the Population Aged 15-64 Years from 1987 to 2006 in China. Int J Environ Res Public Health 2016;13:1033.

8 Sainio P, Martelin T, Koskinen S, Heliövaara M. Educational differences in mobility: the contribution of physical workload, obesity, smoking and chronic conditions. J Epidemiol Community Health 2007;61:401-8.

9 Balaj M, McNamara CL, Eikemo TA, Bambra C. The social determinants of inequalities in self-reported health in Europe: findings from the European social survey (2014) special module on the social determinants of health. Eur J Public Health 2017;27:107-14.

10 Huisman M, Read S, Towriss CA, et al. Socioeconomic inequalities in mortality rates in old age in the World Health Organization Europe region. Epidemiol Rev 2013;35:84-97.

11 Mackenbach JP, Stirbu I, Roskam A-JR, et al. Socioeconomic inequalities in health in 22 European countries. N Engl J Med 2008;358:2468-81.

12 Eikemo TA, Huisman M, Bambra C, Kunst AE. Health inequalities according to educational level in different welfare regimes: a comparison of 23 European countries. Sociol Health Illn 2008;30:565-82.

13 Ross CE, Wu C-l. The links between education and health. Am Sociol Rev 1995;60:719-45.

14 Baker DP, Leon J, Smith Greenaway EG, et al. The education effect on population health: a reassessment. Popul Dev Rev 2011;37:307-32.

15 World Health Organization. International Classification of Functioning, Disability and Health: ICF. Geneva: World Health Organization, 2001.

16 Marmot M, Wilkinson RG. Psychosocial and material pathways in the relation between income and health: a response to Lynch et al. BMJ 2001;322:1233.

17 Eikemo TA, Bambra C, Huijts T, Fitzgerald R. The first pan-European sociological health inequalities survey of the general population: the European Social Survey rotating module on the social determinants of health. Eur Sociol Rev 2017;33:137-53.

18 Fitzgerald R, Jowell R, Measurement equivalence in comparative surveys: the European Social Survey (ESS) — from design to implementation and beyond. In: Harkness J, Braun M, Edwards B, Johnson T, Lyberg L, Mohler P, Pennell B, Smith T, editors. Survey Methods in Multinational, Multiregional, and Multicultural Contexts. Hoboken, New Jersey, Canada: John Wiley \& Sons, 2010: 485-95.

19 Jagger C, Gillies C, Cambois E, et al. The Global Activity Limitation Index measured function and disability similarly across European countries. J Clin Epidemiol 2010;63:892-9.

20 Berger N, Van Oyen H, Cambois E, et al. Assessing the validity of the Global Activity Limitation Indicator in fourteen European countries. BMC Med Res Methodol 2015;15:1.

21 Van Oyen H, Bogaert P, Yokota RT, Berger N. Measuring disability: a systematic review of the validity and reliability of the Global Activity Limitations Indicator (GALI). Arch Public Health 2018;76:25.

22 Schneider SL. The International Standard Classification of Education 2011. Class and Stratification Analysis. Bingley, West Yorkshire: Emerald Group Publishing Limited, 2013: 365-79. 
23 Huijts T, Gkiouleka A, Reibling N, et al. Educational inequalities in risky health behaviours in 21 European countries: findings from the European social survey (2014) special module on the social determinants of health. Eur J Public Health 2017;27:63-72

24 European Social Survey Round 7. Weighting ESS Data, 2014. Available at: www. europeansocialsurvey.org (20 March 2018, date last accessed).

25 Billiet J, Philippens M, Fitzgerald R, Stoop I. Estimation of nonresponse bias in the European Social Survey: using information from reluctant respondents. J Off Stat 2007;23:35.

26 Couper MP, De Leeuw ED, Nonresponse in cross-cultural and cross-national surveys. In: Harkness J, Vijver V, Mohler P, editors. Cross-Cultural Survey Methods. Hoboken, NJ: Wiley-Interscience, 2003: 157-77.

27 Graciani A, Banegas JR, López-García E, Rodríguez-Artalejo F. Prevalence of disability and associated social and health-related factors among the elderly in Spain: a population-based study. Maturitas 2004;48:381-92.

28 Koponen P, Aromaa A. Survey Design and Methodology in National Health Interview and Health Examination Surveys. Review of Literature, European Survey Experiences and Recommendations 2003. Available at: http://ec.europa.eu/health/ph_projects/ 2000/monitoring/monitoring_project_2000_full_en.htm\#4 (20 March 2018, date last accessed).

29 Hämmig O, Gutzwiller F, Kawachi I. The contribution of lifestyle and work factors to social inequalities in self-rated health among the employed population in Switzerland. Soc Sci Med 2014;121:74-84.

30 Gibson M, Petticrew M, Bambra C, et al. Housing and health inequalities: a synthesis of systematic reviews of interventions aimed at different pathways linking housing and health. Health Place 2011;17:175-84.
31 Stronks K, Van De Mheen HD, Looman CW, Mackenbach JP. Behavioural and structural factors in the explanation of socio-economic inequalities in health: an empirical analysis. Sociol Health Illn 1996;18:653-74.

32 Stuck AE, Walthert JM, Nikolaus T, et al. Risk factors for functional status decline in community-living elderly people: a systematic literature review. Soc Sci Med 1999;48:445-69.

33 Manini TM, Beavers DP, Pahor M, et al. Effect of Physical Activity on Self-Reported Disability in Older Adults: results from the LIFE Study. J Am Geriatr Soc 2017;65:980-8.

34 Artaud F, Sabia S, Dugravot A, et al. Trajectories of unhealthy behaviors in midlife and risk of disability at older ages in the whitehall II cohort study. J Gerontol A Biol Sci Med Sci 2016;71:1500-6.

35 Stansfeld S, Head J, Fuhrer R, et al. Social inequalities in depressive symptoms and physical functioning in the Whitehall II study: exploring a common cause explanation. J Epidemiol Community Health 2003;57:361-7.

36 Eide AH, Loeb ME, Nhiwatiwa S, et al. Living conditions among people with disabilities in developing countries. In: Eide AH, Ingstad B, Disability and Poverty: A Global Challenge. Bristol, UK: Policy Press, 2011: 55-70. Available at: http://dx.doi. org/10.1332/policypress/9781847428851.003.0004 (6 July 2018, date last accessed).

37 Mackenbach JP. The persistence of health inequalities in modern welfare states: the explanation of a paradox. Soc Sci Med 2012;75:761-9.

38 Montez JK, Zajacova A, Hayward MD. Disparities in disability by educational attainment across US states. Am J Public Health 2017;107:1101-8.

39 Huijts T, Stornes P, Eikemo TA, Bambra C. The social and behavioural determinants of health in Europe: findings from the European Social Survey (2014) special module on the social determinants of health. Eur J Public Health 2017;27:55-62.

The European Journal of Public Health, Vol. 29, No. 4, 647-655

(C) The Author(s) 2019. Published by Oxford University Press on behalf of the European Public Health Association.

This is an Open Access article distributed under the terms of the Creative Commons Attribution License (http://creativecommons.org/licenses/ by/4.0/), which permits unrestricted reuse, distribution, and reproduction in any medium, provided the original work is properly cited. doi:10.1093/eurpub/ckz010 Advance Access published on 13 February 2019

\title{
All-cause and cause-specific mortality in Scotland 1981-2011 by age, sex and deprivation: a population-based study
}

\author{
Denise Brown, Mirjam Allik, Ruth Dundas, Alastair H. Leyland \\ MRC/CSO Social and Public Health Sciences Unit, University of Glasgow, Glasgow, UK
}

Correspondence: Denise Brown, MRC/CSO Social and Public Health Sciences Unit, University of Glasgow, Glasgow G2 3AX, UK, Tel: +44 (0) 141353 7584, Fax: +44 (0) 141332 0725, e-mail: denise.brown@glasgow.ac.uk

Background: Average life expectancy has stopped increasing for many countries. This has been attributed to causes such as influenza, austerity policies and deaths of despair (drugs, alcohol and suicide). Less is known on the inequality of life expectancy over time using reliable, whole population, data. This work examines all-cause and cause-specific mortality rates in Scotland to assess the patterning of relative and absolute inequalities across three decades. Methods: Using routinely collected Scottish mortality and population records we calculate directly age-standardized mortality rates by age group, sex and deprivation fifths for all-cause and cause-specific deaths around each census 1981-2011. Results: All-cause mortality rates in the most deprived areas in 2011 (472 per 100000 population) remained higher than in the least deprived in 1981 (422 per 100000 population). For those aged 0-64, deaths from circulatory causes more than halved between 1981 and 2011 and cancer mortality decreased by a third (with greater relative declines in the least deprived areas). Over the same period, alcoholand drug-related causes and male suicide increased (with greater absolute and relative increases in more deprived areas). There was also a significant increase in deaths from dementia and Alzheimer's disease for those aged 75+. Conclusions: Despite reductions in mortality, relative (but not absolute) inequalities widened between 1981 and 2011 for all-cause mortality and for several causes of death. Reducing relative inequalities in Scotland requires faster mortality declines in deprived areas while countering increases in mortality from causes such as drug- and alcohol-related harm and male suicide. 